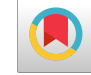

\title{
A Comparative Study of Risperidone and Aripiprazole in Attention Deficit Hyperactivity Disorder in Children Under Six Years Old: A Randomized Double-Blind Study
} Katayoon Razjouyan, ${ }^{1}$ Arash Danesh, ${ }^{1}$ Mojgan Khademi, ${ }^{1}$ Rozita Davari-Ashtiani, ${ }^{1}$ and Simasadat Noorbakhsh, ${ }^{1, *}$

${ }^{1}$ Department of Child and Adolescent Psychiatry, Behavioral Sciences Research Center, Shahid Beheshti University of Medical Sciences, Tehran, Iran

"Corresponding author: Simasadat Noorbakhsh, Behavioral Sciences Research Center, Shahid Beheshti University of Medical Sciences, Tehran, Iran. Tel: +98-2177553074, E-mail: sima.noorbakhsh@sbmu.ac.ir

Received 2017 October 08; Revised 2017 December 28; Accepted 2018 January 17.

\begin{abstract}
Background: Stimulants are not very effective on attention deficit hyperactivity disorder (ADHD) children under 6 years old. The most common medication that is used in this range of age is Risperidone. Evaluating the safety and efficacy of Aripiprazole versus Risperidone for treating children under 6 years suffering from ADHD was the aim of this study.

Methods: During this double-blind clinical trial, 34 children aged 3 - 6 years who were diagnosed with ADHD, received treatments with Aripiprazole or Risperidone randomly for 12 weeks. Follow-up measures comprised, CGAS, the ADHD-RS, CPRS and side effect checklist.

Results: The findings revealed that 20 patients in Risperidone group (including 13 boys and 7 girls) and 20 patients in Aripiprazole group (including 13 boys and 7 girls) had at least one follow-up examination. After 12 weeks of the study, both medications showed distinct improvements in ADHD RS $(\mathrm{P}<0.001)$, CPRS $(\mathrm{P}<0.001)$ and CGAS $(\mathrm{P}<0.001)$ scores. The statistic difference between them was not significantly different. The most common side effects in Risperidone group were reported to be panic (20\%), nausea and vomiting (20\%), while in Aripiprazole they were reported to be increased appetite (25\%) and somnolence (15\%).

Conclusions: The findings revealed that both Risperidone and Aripiprazole are effective in treating ADHD children under 6 years old and there was no significant difference between the two drugs. Children can tolerate them well. Aripiprazole effect on children showed itself earlier compared to Risperidone.
\end{abstract}

Keywords: Attention Deficit Disorder with Hyperactivity, Risperidone, Aripiprazole, Antipsychotic Agents, Attention, Clinical Trial, Children

\section{Background}

Mostly characterized by symptoms like hyperactivity, inattention and impulsivity (1), attention deficit hyperactivity disorder (ADHD) is one of the most common neurobehavioral disorders in childhood (2). Its worldwide prevalence in children is estimated to be $5.29 \%$ (1). Although stimulants, tricyclics and noradrenergics are ineffective on some patients or some patients cannot tolerate them, they are usually used to manage it. Hence there must be some alternative medications to be applied on this sample of ADHA children.

Stimulants are the first line medication for most of ADHD children. Although the effect of psycho-stimulants in children under 6 years are less compared to older age (2). Besides, they experience more side effects of stimulants and increasingly turn to switch to other medications like antipsychotics $(2,3)$. Haloperidol and Largactil are the two first approved medications in USA for short-term control of ADHD in children (4). Although, because of different side effects treatment is switching toward newer antipsychotics like Risperidone, with fewer side effects profile in short and long term (5).

A study by the national ambulatory medical care survey and the national hospital ambulatory found that ADHD was the most common diagnosis in prescription of antipsychotics in children aged 2 to 18 years from 1995 to 2002 (6). However, there are a few evidences from controlled studies that support the use of newer antipsychotics for behavioral conditions such as $\operatorname{ADHD}(7)$. The most atypical antipsychotics examined in children with ADHD or conduct disorder is Risperidone (8). In many studies, ADHD was associated with different diagnoses like mental retardation, oppositional defiant disorder, bipolar mood disorder and

Copyright (c) 2018, Iranian Journal of Pediatrics. This is an open-access article distributed under the terms of the Creative Commons Attribution-NonCommercial 4.0 International License (http://creativecommons.org/licenses/by-nc/4.0/) which permits copy and redistribute the material just in noncommercial usages, provided the original work is properly cited. 
tic disorder. In case of Aripiprazole, studies are even less. In addition, none of them are conducted in preschool children and the age group ranges from 6 to 18 years.

Aripiprazole is a partial dopamine agonist which has a special mechanism. It is a more recent antipsychotic and in hyperdopaminergic conditions acts as an antagonist to dopamine D2 receptors (9). Moreover, it is known as the partial agonist of 5-HT1A receptor which explains the antiOCD characteristics of Aripiprazole (10). It is also the antagonist of 5HT2A receptor which can worsen OCD symptoms (11). Aripiprazole can also be a good alternative for other antipsychotics in children who experienced significant metabolic side effects (12).

\section{Objectives}

The purpose of this randomized, double blind, placebo controlled study was to evaluate and compare the efficacy and safety of two atypical antipsychotics, Risperidone and Aripiprazole in ADHD children under six years old.

\section{Methods}

This randomized, parallel group, double-blinded and placebo-controlled was clinical trial was accomplished in Imam Hossein hospital, Shahid Beheshti University of Medical Sciences in Tehran/Iran, from August 2013 to May 2015. The population of this research included all ADHD children admitted to psychiatry ward of the Hospital. The under study patients were diagnosed based on the DSM-IV-TR (13).

The inclusion criteria were ADHD patients from both genders based on DSM-IV-TR criteria aged three to six years who were indicated for treatment by either Risperidone or Aripiprazole by a psychiatrist. They were excluded from study if they had any comorbidities like bipolar disorder, psychotic disorder, mental retardation, developmental delay disorders, autistic disorder, or epilepsy. They also had to take no psychotropic medication two weeks prior to the study.

Performing the structured interview, some of the patients were diagnosed with ADHD. Those who were volunteered to attend in this study and also met the inclusion criteria entered the research. Afterwards an informing session was held for their parents and after providing written consents, the participants were registered.

There was an attempt among the two groups to reject the null hypothesis of no difference treatment between Risperidone and Aripiprazole, at $\alpha$ of $0.05, \beta$ of 0.6 , and standard effect size of 0.5 . Finally, 47 patients were ready to attend the study. Thus, twenty four individuals were allocated to each group.
Before beginning the study, patient's guardians were presented a full explanation about the study procedure, possible side effects and interventions. Besides, patient's autonomy and their free will to leave the study whenever they wanted was conducted to their guardians. Furthermore, the legal guardians were asked to sign the written consent form which was according to the declaration of Helsinki. All treatment of this study was free of charge for the patients. The ethics committee of Shahid Beheshti University of Medical Sciences (No. 9169) approved the study and afterwards it was registered in Iranian center of clinical trial registration (IRCT IRCT2013050413215N1).

The patients were assigned to one of Risperidone or Aripiprazole group randomly (1:1) using an automated system. A random number generator was used in order to randomize patients in $\mathrm{A}$ (Risperidone) and $\mathrm{B}$ (Aripiprazole) groups. Treatment allocation was not known to participants, study team, and staff. Placebo tablets and active drugs were similar in appearance. To ensure masking, just one psychiatrist knew the content of the drug capsules. Counseling and data collection were done by a trained psychiatry resident, who was also masked.

\subsection{Pharmacological Intervention}

In this study a flexible titration procedure was used. Thus we adjusted individually the dose for optimal efficacy and tolerability. The first group took Risperidone plus Aripiprazole as placebo. The starting dose was 0.25 mg of Risperidone and one fourth of Aripiprazole placebo. Dosage increased every other week by $0.25 \mathrm{mg}$ of Risperidone and one fourth of placebo pill according to the child response or observing side effects. The maximum dose of Risperidone was $1 \mathrm{mg} /$ day orally and one tablet of Aripiprazole placebo pill. In second group, the starting dosage of Aripiprazole was $1.25 \mathrm{mg}$ daily and it was increased $1.25 \mathrm{mg}$ every other week depending on the child response or observed side effects. The maximum dose of Aripiprazole was $5 \mathrm{mg}$ once a day orally and one complete tablet of Risperidone placebo.

\subsection{Assessment of Efficacy and Side Effects}

Assessments were performed at baseline and week 2, week 4 , week 8 , and week 12 . The very first results of measures for assessing ADHD symptoms were the ADHD rating scale-IV (ADHD RS-IV) and the conners parent rating scale (CPRS). The ADHD RS-IV is a norm-referenced checklist that measures the symptoms of ADHD according to the DSM-IV (14). This scale aims to provide a means of gathering information about the frequency of certain behaviors, based on the reports of parents and teachers over the past 6 months. The 18-item questionnaire has two subscales (inattention 
and hyperactivity-impulsivity) and takes approximately 5 minutes to complete. The CPRS can be described as a behavioral scale which is used in clinical and research settings that deal with children suffering from neurodevelopmental disorders, or better said, with children suffering from ADHD. CPRS provides clinicians and researchers with qualitative and quantitative information about children's behavioral and emotional attitudes. It includes five different subscales, each measuring learning problems, anxiety, conduct problems, impulsive/hyperactive behavior and psychosomatic feelings (15). We asked the parents to complete them at baseline, week 2, week 4, week 8, and week 12.

We also applied two instruments by which we assessed the participants' level of performance and side effects of drugs. The children's global assessment scale (CGAS) that was fielded in all five phases of assessments, is a numeric scale used by mental health clinicians to rate the overall functional status of children and adolescents under the age of 18. Scores run from zero to 100, with high scores indicating better functioning. Although this is a valid and reliable test (16), ratings on a CGAS should be independent of specific mental health diagnoses (17). A checklist for side effects was made by authors according to the mentioned side effects of each drug in the text book (15).

\subsection{Data Analysis}

The mean, standard deviation, frequency, percentage, median, and range were used to describe data. To evaluate the difference between the two groups (from baseline), Mann-Whitney test, Chi-square and t-test were used. The ANCOVA (analysis of covariance) was used for tracking metrics of comparing results between the two groups of the test.

To compare the results between the two groups during follow up compared to baseline data Mixed ANOVA was used. To calculate the effect size in follow up for each group, the mean score of the assessment criteria at the end and beginning of the study was divided to their standard deviations. For comparison between two groups, partial ETA squared of group effect in analysis of covariance was used. Effect size equivalent to 0.2 was considered as little, 0.4 as medium, and 0.6 as large.

$P$ value of less than 0.05 was considered statistically significant. All statistical analyses were done by software SPSS (version 17, SPSS Inc., Chicago IL).

\section{Results}

Forty-eight children three to six years old were recruited in the study. Twenty-five children were placed randomly at group one and 23 children put in the second group. Eight children (three in group one and five in group two) did not return for following up after receiving medication and were excluded from study (Figure 1).

There were no significant differences for age, sex, previous history of physical health problems and previous ADHD treatment.

The difference of ADHD total score at baseline was not significant between two groups $(\mathrm{P}=0.351)$. Subgroups of inattention and hyperactivity/impulsivity were analyzed separately. At the end of the week 12, ADHD symptoms significantly decreased in both Risperidone and Aripiprazole groups. In Aripiprazole group, the score declined from 27.3 \pm 6.6 to $14 \pm 7.9(\mathrm{ES}=1.72, \mathrm{P}<0.001)$ and in Risperidone group from $29 \pm 6.4$ to $16.9 \pm 7.4$ ( $E S=1.80, \mathrm{P}<0.001$ ) (Table 1). The final difference between these two groups was not significant $(\mathrm{P}=0.761)$. The only significant difference between two groups was seen at second week in Aripiprazole group: drop in ADHD total score and subscales was faster $(\mathrm{P}<0.05)$.

The function of children based on CGAS score increased in both Risperidone and Aripiprazole groups (Table 2). This increase was statistically significant in both groups $(\mathrm{P}<0.001)$. The only obvious difference was observed in the second week: the improvement in the Aripiprazole group was higher than Risperidone group and this difference was statistically significant $(\mathrm{P}=0.006)$ and compared with baseline, Aripiprazole group showed also a significant increase in the second week $(\mathrm{P}<0.001, \mathrm{ES}=$ 1.54). However, despite the slowness of improvement in the second week of the Risperidone group, its significant performance increased from the fourth week $(\mathrm{P}<0.001)$.

In both Aripiprazole and Risperidone groups total CPRS at the end of the week 12 had lower scores compared with baseline, and this decline was statistically significant in both groups $(\mathrm{P}<0.001)$ (Table 3$)$. The reduction of symptoms was significant from week 2 in both groups. Conduct problem sub-score of Total CPRS in both groups declined at the end of the week 12 compared to baseline $(\mathrm{P}<0.001)$. Drop in this subscale was significant from week 2 in both groups. In subscale of learning problem in Total CPRS, both groups showed a decline at the end of week 12 compared to baseline $(\mathrm{P}<0.001)$. Decrease in this subscale was significant from week 4 in both groups. The psychosomatic subscale of total CPRS decreased in both groups compared with baseline at the end of the week 12, but the drop was statistically significant only in the Risperidone group $(\mathrm{P}=$ 0.044 ) not in Aripiprazole group. Both the Impulsivity and Hyperactivity subscale of Conner's lowered compared to baseline in both groups (in both groups $\mathrm{P}<0.001$ ). Decrease in the subscales of both Risperidone and Aripiprazole groups occurred after four weeks. Hyperactivity Index in both groups was lowered compared to baseline at 


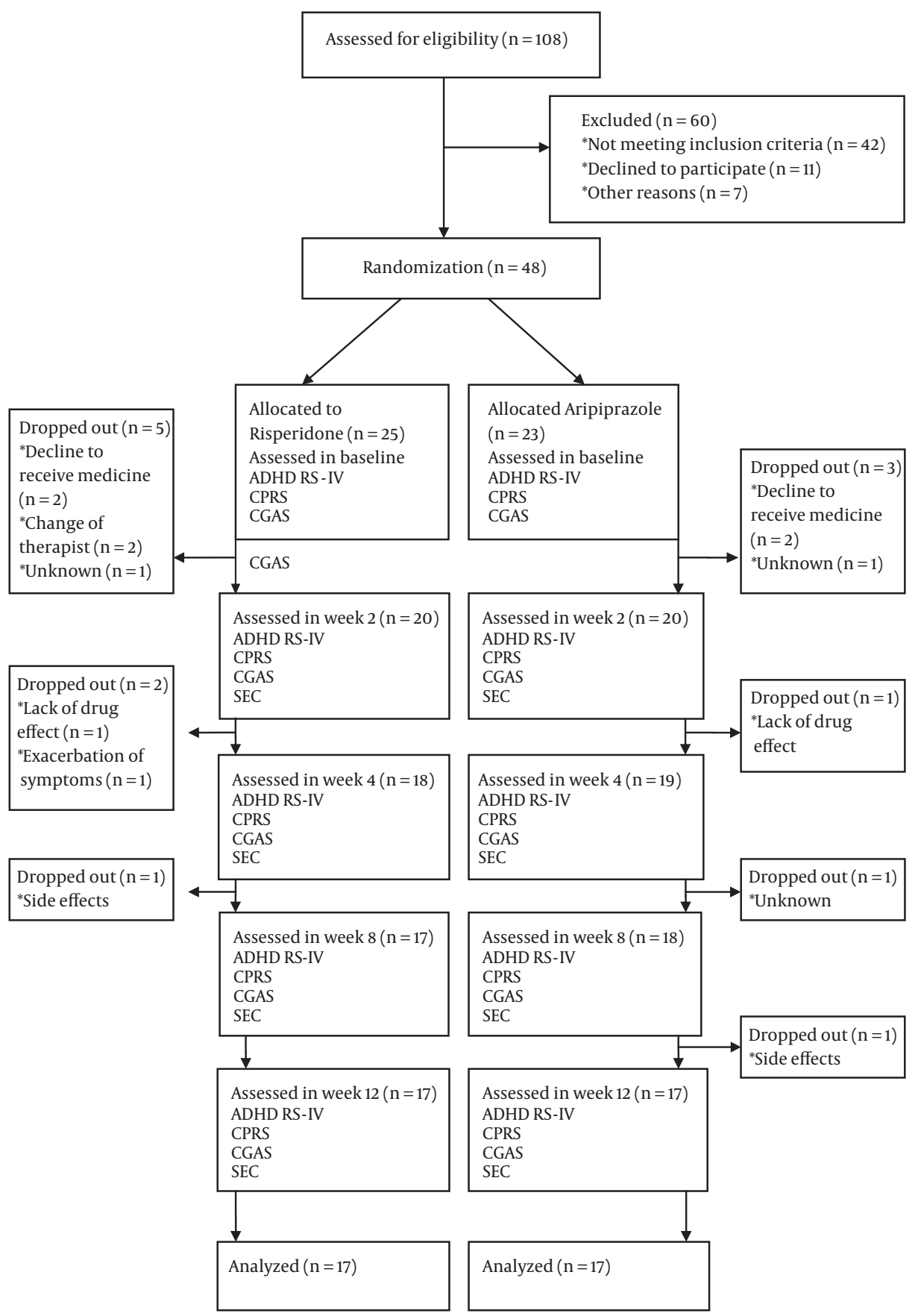

Figure 1. Intervention Scheme/ Trial Flow Diagram

the end of the week 12 and this reduction was statistically significant in both groups $(\mathrm{P}<0.001)$. Decrease was significant in both Risperidone and Aripiprazole group after week 2 .

The most common side effects in the Risperidone group were urinary incontinence (20\%), irritability (15\%), 
Table 1. Changes in ADHD RS Scores Between the Two Groups During the Study

\begin{tabular}{|c|c|c|c|c|c|c|}
\hline & \multicolumn{2}{|c|}{$\mathbf{I}$} & \multicolumn{2}{|c|}{ II } & \multicolumn{2}{|c|}{ Comparison $^{a}$} \\
\hline & Mean \pm SD & $\mathbf{E S}^{\mathbf{b}}$ & Mean \pm SD & $\mathbf{E S}^{\mathbf{b}}$ & $\mathbf{E S}^{\mathbf{c}}$ & $\mathbf{P}$ \\
\hline \multicolumn{7}{|l|}{ Inattentive } \\
\hline Base & $10.5 \pm 3.1$ & - & $11.5 \pm 2.5$ & - & & \\
\hline Week 2 & $8.2 \pm 3.5$ & 0.93 & $10.4 \pm 2.8$ & 0.41 & 0.08 & 0.088 \\
\hline Week 4 & $6.7 \pm 2.8$ & 1.22 & $8.7 \pm 3.3$ & 0.86 & 0.05 & 0.188 \\
\hline Week 8 & $5.3 \pm 3.3$ & 1.43 & $7.5 \pm 2.7$ & 1.63 & 0.05 & 0.211 \\
\hline Week 12 & $5.1 \pm 3.4$ & 1.41 & $7.1 \pm 3.4$ & 1.61 & 0.02 & 0.472 \\
\hline \multicolumn{7}{|c|}{ Hyperactivity/Impulsivity } \\
\hline Base & $16.8 \pm 4$ & - & $17.5 \pm 2.8$ & - & & \\
\hline Week 2 & $12.7 \pm 4.7$ & 1.31 & $15.5 \pm 3.5$ & 0.69 & 0.13 & 0.024 \\
\hline Week 4 & $11 \pm 4$ & 1.97 & $11.9 \pm 4.4$ & 1.21 & 0.00 & 0.777 \\
\hline Week 8 & $9.4 \pm 4.6$ & 1.60 & $10.8 \pm 4.3$ & 1.36 & 0.01 & 0.613 \\
\hline Week 12 & $8.9 \pm 4.7$ & 1.71 & $9.8 \pm 5$ & 1.42 & 0.00 & 0.936 \\
\hline \multicolumn{7}{|l|}{ Total } \\
\hline Base & $27.3 \pm 6.6$ & - & $29 \pm 4.6$ & - & & \\
\hline Week 2 & $20.9 \pm 7.7$ & 1.27 & $25.9 \pm 5.9$ & 0.63 & 0.12 & 0.033 \\
\hline Week 4 & $17.7 \pm 6.2$ & 2.07 & $20.6 \pm 6.9$ & 1.30 & 0.01 & 0.506 \\
\hline Week 8 & $14.7 \pm 7.9$ & 1.63 & $18.2 \pm 5.8$ & 1.84 & 0.02 & 0.456 \\
\hline Week 12 & $14 \pm 7.9$ & 1.72 & $16.9 \pm 7.4$ & 1.80 & 0.00 & 0.842 \\
\hline \multicolumn{7}{|c|}{$\begin{array}{l}\text { Abbreviation: ES, Effect Size. } \\
\text { a Adjusted for the baseline, based on analysis of covariance (ANCOVA). } \\
\text { b } \text { The mean difference at the end of study from the start was divided by standard deviation of changes. } \\
\text { c Calculated as Partial Eta Squared of group in analysis of covariance. }\end{array}$} \\
\hline
\end{tabular}

Table 2. Changes in CGAS Scores During the Study

\begin{tabular}{|c|c|c|c|c|c|}
\hline & \multicolumn{2}{|c|}{ I } & \multicolumn{2}{|c|}{ II } & \multirow[t]{2}{*}{$\mathbf{P}^{\mathbf{a}}$} \\
\hline & Mean \pm SD & ES & Mean $\pm S D$ & ES & \\
\hline Base & $48 \pm 7$ & & $46 \pm 6$ & & 0.367 \\
\hline Week 2 & $59 \pm 10$ & 1.54 & $50 \pm 11$ & 0.32 & 0.006 \\
\hline Week 4 & $65 \pm 11$ & 1.82 & $61 \pm 12$ & 1.42 & 0.385 \\
\hline Week 12 & $72 \pm 13$ & 1.50 & $67 \pm 13$ & 1.92 & 0.349 \\
\hline
\end{tabular}

${ }^{\text {a }}$ Based on Mann-Whitney test.

fear (15\%), nausea (15\%), and vomiting (15\%). The most common side effects in Aripiprazole group were increased appetite (20\%), somnolence (15\%), and irritability (15\%) (Table $4)$. The comparison between the most common side effects in these two groups showed no significant difference $(\mathrm{P}>$ 0.05).

\section{Discussion}

The purpose of the study was to compare Aripiprazole and Risperidone in ADHD children under 6 years old. According to the results of the study, both Aripiprazole and Risperidone were effective in overall performance and lessening of ADHD symptoms, and there was no significant difference between the two drugs. Although the signs of the 
Table 3. Changes in Conner's Scale During the Study

\begin{tabular}{|c|c|c|c|c|c|c|c|}
\hline & & \multicolumn{2}{|c|}{ I } & \multicolumn{2}{|c|}{ II } & \multicolumn{2}{|c|}{ Comparison $^{\mathrm{a}}$} \\
\hline & & Mean \pm SD & ESa & Mean \pm SD & ESa & ESb & $\mathbf{P}$ \\
\hline \multirow{5}{*}{ Conduct problem } & Base & $68 \pm 10$ & - & $78 \pm 13$ & - & & \\
\hline & Week 2 & $62 \pm 11$ & 0.70 & $74 \pm 13$ & 0.48 & 0.05 & 0.199 \\
\hline & Week 4 & $58 \pm 13$ & 1.32 & $64 \pm 16$ & 1.01 & 0.00 & 0.685 \\
\hline & Week 8 & $52 \pm 12$ & 1.18 & $60 \pm 13$ & 1.45 & 0.01 & 0.625 \\
\hline & Week 12 & $51 \pm 12$ & 1.91 & $59 \pm 14$ & 1.33 & 0.00 & 0.755 \\
\hline \multirow{5}{*}{ Learning problem } & Base & $74 \pm 15$ & - & $81 \pm 11$ & - & & \\
\hline & Week 2 & $69 \pm 16$ & 0.48 & $77 \pm 14$ & 0.28 & 0.01 & 0.560 \\
\hline & Week 4 & $62 \pm 17$ & 0.96 & $72 \pm 13$ & 0.83 & 0.02 & 0.369 \\
\hline & Week 8 & $61 \pm 19$ & 0.74 & $66 \pm 14$ & 1.05 & 0.00 & 0.986 \\
\hline & Week 12 & $58 \pm 16$ & 0.89 & $64 \pm 13$ & 1.29 & 0.01 & 0.667 \\
\hline \multirow{5}{*}{ Psychosomatic } & Base & $48 \pm 13$ & - & $53 \pm 19$ & - & & \\
\hline & Week 2 & $50 \pm 14$ & -0.15 & $49 \pm 13$ & 0.27 & 0.03 & 0.325 \\
\hline & Week 4 & $47 \pm 9$ & -0.10 & $52 \pm 17$ & 0.15 & 0.00 & 0.713 \\
\hline & Week 8 & $44 \pm 0$ & 0.24 & $46 \pm 8$ & 0.30 & 0.04 & 0.264 \\
\hline & Week 12 & $44 \pm 0$ & 0.24 & $44 \pm 0$ & 0.47 & 0.00 & 0.000 \\
\hline \multirow{5}{*}{ Impulsive/Hyperactive } & Base & $66 \pm 7$ & - & $69 \pm 8$ & - & & \\
\hline & Week 2 & $61 \pm 11$ & 0.40 & $67 \pm 11$ & 0.14 & 0.05 & 0.185 \\
\hline & Week 4 & $55 \pm 12$ & 0.70 & $61 \pm 14$ & 0.59 & 0.04 & 0.256 \\
\hline & Week 8 & $54 \pm 13$ & 0.71 & $55 \pm 9$ & 1.33 & 0.00 & 0.799 \\
\hline & Week 12 & $52 \pm 7$ & 1.89 & $53 \pm 10$ & 1.64 & 0.00 & 0.832 \\
\hline \multirow{5}{*}{ Anxiety } & Base & $47 \pm 6$ & - & $52 \pm 8$ & - & & \\
\hline & Week 2 & $48 \pm 6$ & -0.22 & $50 \pm 6$ & 0.46 & 0.02 & 0.448 \\
\hline & Week 4 & $48 \pm 5$ & -0.21 & $51 \pm 5$ & 0.19 & 0.00 & 0.696 \\
\hline & Week 8 & $48 \pm 3$ & -0.08 & $52 \pm 5$ & 0.15 & 0.09 & 0.083 \\
\hline & Week 12 & $49 \pm 2$ & -0.17 & $49 \pm 4$ & 0.45 & 0.00 & 0.844 \\
\hline \multirow{5}{*}{ Hyperactivity/Index } & Base & $73 \pm 10$ & - & $79 \pm 9$ & - & & \\
\hline & Week 2 & $65 \pm 12$ & 0.91 & $74 \pm 11$ & 0.59 & 0.06 & 0.133 \\
\hline & Week 4 & $59 \pm 12$ & 1.91 & $65 \pm 14$ & 1.04 & 0.00 & 0.703 \\
\hline & Week 8 & $55 \pm 13$ & 1.48 & $60 \pm 12$ & 1.40 & 0.01 & 0.591 \\
\hline & Week 12 & $54 \pm 13$ & 1.74 & $58 \pm 13$ & 1.91 & 0.01 & 0.576 \\
\hline \multirow{5}{*}{ Total CPRS } & Base & $376 \pm 42$ & - & $412 \pm 46$ & - & & \\
\hline & Week 2 & $355 \pm 48$ & 0.70 & $392 \pm 40$ & 0.59 & 0.02 & 0.447 \\
\hline & Week 4 & $329 \pm 47$ & 1.39 & $365 \pm 60$ & 0.91 & 0.00 & 0.729 \\
\hline & Week 8 & $313 \pm 46$ & 1.27 & $339 \pm 43$ & 1.34 & 0.01 & 0.511 \\
\hline & Week 12 & $307 \pm 44$ & 1.69 & $327 \pm 48$ & 1.70 & 0.00 & 0.865 \\
\hline
\end{tabular}

${ }^{a}$ Calculated as Partial Eta Squared of group in analysis of covariance.

declining trend continued until the end of the week 12 in both groups, the highest rate of change was seen in the sec- ond and fourth weeks, and the reduction of symptoms was stable to the end of the week 12 . 


\begin{tabular}{|c|c|c|}
\hline Side Effect & Frequency & Percent \\
\hline \multicolumn{3}{|l|}{ Aripiprazole } \\
\hline Appetite & 4 & 20 \\
\hline Drowsiness & 3 & 15 \\
\hline Dysphoria & 3 & 15 \\
\hline Irritability & 2 & 10 \\
\hline Nausea and vomiting & 1 & 5 \\
\hline Weaknesses & 1 & 5 \\
\hline Screaming & 1 & 5 \\
\hline Weight gain & 1 & 5 \\
\hline Compulsive washing & 1 & 5 \\
\hline Vertigo & 1 & 5 \\
\hline Aggression & 1 & 5 \\
\hline \multicolumn{3}{|l|}{ Risperidone } \\
\hline Incontinence & 4 & 20 \\
\hline Nausea and vomiting & 3 & 15 \\
\hline Irritability & 3 & 15 \\
\hline Fear & 3 & 15 \\
\hline Frequent urination & 2 & 10 \\
\hline Headache & 1 & 5 \\
\hline Drowsiness & 1 & 5 \\
\hline Aggression & 1 & 5 \\
\hline Appetite & 1 & 5 \\
\hline Weight gain & 1 & 5 \\
\hline Cramp & 1 & 5 \\
\hline Weakness & 1 & 5 \\
\hline Screaming & 1 & 5 \\
\hline Flushing & 1 & 5 \\
\hline Insomnia & 1 & 5 \\
\hline Vibration & 1 & 5 \\
\hline Talkativeness & 1 & 5 \\
\hline Teeth grinding & 1 & 5 \\
\hline Irritability & 1 & 5 \\
\hline Akathesia & 1 & 5 \\
\hline
\end{tabular}

The dose of both drugs was increased further up to four weeks, but in spite of not increasing the mean dose of Aripiprazole after four weeks, the dose of Risperidone titrated from 0.73 in the fourth week up to 0.82 in week 12 . The difference was not statistically significant. The need to increase the dose of Risperidone may be related to its tolerance.
The only noticeable difference was early Aripiprazole effect in the second week. It reduced all subscales earlier than Risperidone. In children with severe symptoms that require rapid response, Aripiprazole is a better choice, although at the end of the week 12, there was no difference between these two drugs.

The scores of CGAS showed that both drugs led to marked improvement in performance. There was no significant difference between these two medications at the end of the week 12. Interestingly, the only difference was the faster response in Aripiprazole group. The response started at the second week in Aripiprazole compared to the fourth week in Risperidone group.

Assessment of symptoms by CPRS showed similar results. At the end of the week 12, both medications were effective in reducing overall score of CPRS. The differences between these two groups were not significant. Reducing symptoms in both groups was significant from week 2. The four subscales showed similar results as in the overall score. These scores declined at the end of the week 12 as a result of treatment with either Risperidone or Aripiprazole. These reductions are statistically significant for both drugs. A previous study on Aripiprazole demonstrated the same results on behavioral problems in children with autism, aged 6 - 17 years (18). Another study by Masy et al. (19) on children with Tourette's disorder and comorbid ADHD showed moderately improvement of symptoms while OCD comorbidity was associated with better results.

In the study of Findling et al. (20), the most common side effects of Aripiprazole in children 8 to 12 years old with ADHD, were drowsiness (78\%) and headache (47\%). In this study, the results were somehow different. The most common side effect of Aripiprazole was high appetite and gaining weight. It was even higher than in Risperidone group that can make trouble in children who are at high risk for obesity and metabolic disorders. In study of Correia Filho et al. (21) over children aged six to 12 with ADHD and mental retardation the most common side effects of Risperidone were drowsiness and weight gain compared to baseline, which is in line with that of ours. However, in these cases the most common side effect was urinary incontinency. It occurred in children who had bladder control before starting medication. It could be an unpleasant symptom for children and their family and push them to terminate the medication.

The results of this study showed that both drugs, Risperidone and Aripiprazole, are well tolerated in ADHD children aged less than six years old. Minimal side effects without serious problem is reported for both groups. Because of short-term duration of treatment, it was not possible to assess possible tolerability to side effects.

Number of children in this study was limited, espe- 
cially because we needed their parents' consent to continue. The most reluctant parents were fathers. The treatment lasted only 3 months. Indeed, to obtain better results and examine long-term effects of medication it is better to spend longer time for the study. Urinary incontinency during treatment is recommended to make sure this side effect does not become the first complaint. However, further studies are needed to assert this problem and find a proper treatment.

\section{Acknowledgments}

The authors express their gratitude to all participants in the study who made this project possible.

\section{Footnote}

Funding/Support: This study was supported in part by grant No. 9169 from behavioral sciences research center of Shahid Beheshti University of Medical Sciences, Tehran, Iran.

\section{References}

1. Polanczyk G, de Lima MS, Horta BL, Biederman J, Rohde LA. The worldwide prevalence of ADHD: a systematic review and metaregression analysis. Am J Psychiatry. 2007;164(6):942-8. doi: 10.1176/ajp.2007.164.6.942. [PubMed:17541055].

2. Wigal T, Greenhill L, Chuang S, McGough J, Vitiello B, Skrobala A, et al. Safety and tolerability of methylphenidate in preschool children with ADHD. J Am Acad Child Adolesc Psychiatry. 2006;45(11):1294-303. doi: 10.1097/01.chi.0000235082.63156.27. [PubMed: 17028508].

3. Arabgol F, Panaghi L, Nikzad V. Risperidone Versus Methylphenidate in Treatment of Preschool Children With Attention-Deficit Hyperactivity Disorder. Iran J Pediatr. 2015;25(1). e265. doi: 10.5812/ijp.265. [PubMed: 26199694].

4. Seida JC, Schouten JR, Mousavi SS, Hamm M, Beaith A, Vandermeer B, et al. AHRQ Comparative Effectiveness Reviews. First- and SecondGeneration Antipsychotics for Children and Young Adults. Rockville(MD); 2012.

5. Pathak P, West D, Martin BC, Helm ME, Henderson C. Evidencebased use of second-generation antipsychotics in a state Medicaid pediatric population, 2001-2005. Psychiatr Serv. 2010;61(2):123-9. doi: 10.1176/ps.2010.61.2.123. [PubMed: 20123816].

6. Cooper WO, Arbogast PG, Ding H, Hickson GB, Fuchs DC, Ray WA. Trends in prescribing of antipsychotic medications for US children. Ambul Pediatr. 2006;6(2):79-83. doi: 10.1016/j.ambp.2005.11.002. [PubMed: 16530143].
7. Gunther T, Herpertz-Dahlmann B, Jolles J, Konrad K. The influence of risperidone on attentional functions in children and adolescents with attention-deficit/hyperactivity disorder and co-morbid disruptive behavior disorder. J Child Adolesc Psychopharmacol. 2006;16(6):725-35. doi: 10.1089/cap.2006.16.725. [PubMed: 17201616].

8. Pringsheim T, Gorman D. Second-generation antipsychotics for the treatment of disruptive behaviour disorders in children: a systematic review. Can J Psychiatry. 2012;57(12):722-7. doi: 10.1177/070674371205701203. [PubMed: 23228230].

9. Burris KD, Molski TF, Xu C, Ryan E, Tottori K, Kikuchi T, et al. Aripiprazole, a novel antipsychotic, is a high-affinity partial agonist at human dopamine D2 receptors. J Pharmacol Exp Ther. 2002;302(1):381-9. [PubMed: 12065741].

10. Matsushita M, Egashira N, Harada S, Okuno R, Mishima K, Iwasaki K, et al. Perospirone, a novel antipsychotic drug, inhibits marble-burying behavior via 5-HT1A receptor in mice: implications for obsessivecompulsive disorder. J Pharmacol Sci. 2005;99(2):154-9. [PubMed: 16210777].

11. Gao K, Muzina D, Gajwani P, Calabrese JR. Efficacy of typical and atypical antipsychotics for primary and comorbid anxiety symptoms or disorders: a review. J Clin Psychiatry. 2006;67(9):1327-40. [PubMed: 17017818].

12. Greenaway M, Elbe D. Focus on aripiprazole: a review of its use in child and adolescent psychiatry. J Canad Acad Child Adol Psychiatry. 2009;18(3):250.

13. APA.Diagnostic criteria from dsm-iv-tr. American Psychiatric Pub; 2000.

14. Pappas D. ADHD Rating Scale-IV: Checklists, Norms, and Clinical Interpretation. J Psychoeduc Assess. 2016;24(2):172-8. doi: 10.1177/0734282905285792.

15. Sadock BJ, Sadock VA. Kaplan and Sadock's synopsis of psychiatry: Behavioral sciences/clinical psychiatry. Lippincott Williams Wilkins; 2011.

16. Bird HR, Canino G, Rubio-Stipec M, Ribera JC. Further measures of the psychometric properties of the Children's Global Assessment Scale. Arch Gen Psychiatry. 1987;44(9):821-4. [PubMed: 3632256].

17. Shaffer D, Gould MS, Brasic J, Ambrosini P, Fisher P, Bird H, et al. A children's global assessment scale (CGAS). Arch Gen Psychiatry. 1983;40(11):1228-31. [PubMed: 6639293].

18. Owen R, Sikich L, Marcus RN, Corey-Lisle P, Manos G, McQuade RD, et al. Aripiprazole in the treatment of irritability in children and adolescents with autistic disorder. Pediatrics. 2009;124(6):1533-40. doi: 10.1542/peds.2008-3782. [PubMed: 19948625].

19. Masi G, Gagliano A, Siracusano R, Berloffa S, Calarese T, Ilardo G, et al. Aripiprazole in children with Tourette's disorder and co-morbid attention-deficit/hyperactivity disorder: a 12-week, open-label, preliminary study. J Child Adolesc Psychopharmacol. 2012;22(2):120-5. doi: 10.1089/cap.2011.0081. [PubMed: 22375853].

20. Findling RL, Short EJ, Leskovec T, Townsend LD, Demeter CA McNamara NK, et al. Aripiprazole in children with attentiondeficit/hyperactivity disorder. J Child Adolesc Psychopharmacol. 2008;18(4):347-54. doi: 10.1089/cap.2007.0124. [PubMed:18759644].

21. Correia Filho AG, Bodanese R, Silva TL, Alvares JP, Aman M, Rohde LA. Comparison of risperidone and methylphenidate for reducing ADHD symptoms in children and adolescents with moderate mental retardation.J Am Acad Child Adolesc Psychiatry. 2005;44(8):748-55. doi: 10.1097/01.chi.0000166986.30592.67. [PubMed: 16034276]. 